\title{
ASSOCIATIONS BETWEEN LEPTIN, GROWTH FACTORS AND BONE TURNOVER MARKERS IN PREPUBERTAL OBESE CHILDREN
}

\author{
Joanna Gajewska', Jadwiga Ambroszkiewicz', Magdalena Chełchowska', \\ Witold Klemarczyk ${ }^{2}$, Patrycja Kurpińska², Halina Weker ${ }^{2}$, Teresa Laskowska-Klita ${ }^{1}$
}

'Screening Department, ${ }^{2}$ Department of Nutrition, Institute of Mother and Child, Warsaw, Poland

\section{Introduction}

Obesity is the direct cause of a number of immediate problems during childhood. Among them the high prevalence of fractures and joint problems in obese children were observed. Leptin may influence the development and bone remodeling in children, but this phenomenon is not well understood.

Therefore, we studied the relationships between leptin and bone turnover markers, growth factors and anthropometric parameters in obese prepubertal children.

\section{Materials and Methods}

We examined 55 obese ( $z$-score BMI $>2$ ) and 50 non-obese ( $z$-score BMl $<-1+1>$ ) children at the age 5-10 years. The children were recruited from patients who visited Department of Nutrition at the Institute of Mother and Child in Warsaw.

Exclusion criteria were:

(a) the presence of endocrine disorders or genetic syndromes, including syndromic obesity, (b) chronic medical conditions

(c) taking medications that could affect growth, pubertal development and nutritional status. Body composition and total bone mineral density (BMD) were measured by dual-energy X-ray absorptiometry (DXA). Commercially available ELISA kits from DRG (Germany) were using for determining leptin and leptin receptor (sOB-R) concentrations. Activity of bone alkaline phosphatase (BALP) was estimated using kit from Quidel (USA). Osteocalcin (OC) and collagen type I crosslinked C-telopeptide (CTX-I) concentrations were measured with N-MID osteocalcin ELISA kit and serum CrossLaps ELISA (IDS, Great Britain), respectively. Insulin-like growth factor-I (IGF-I), IGF-binding protein-1 (IGFBP-1), IGF-binding protein-3 (IGFBP-3) and functional IGFBP-3 (IGFBP-3f) values were determined by kits from Mediagnost (Germany).

The dietary intake was collected using randomly selected 3-day records. Average daily food rations and their nutritional value were calculated using nutritional computer software (Dietetyk $2 \circledast$, National Food and Nutrition Institute, Warsaw). We assessed the average daily intake of energy and the percentage of energy intake from protein, fat and carbohydrates in diet of obese and non-obese children. Statistical analysis was performed using STATISTICA computer software (version 8.0).

\section{Results}

$\Leftrightarrow$ As shown in Table 1 there are significant differences in the body height, weight, BMI and BMI zscore between obese and non-obese children in the same age. The obese children had above 3 -fold greater $(p<0.001)$ fat mass and 2 -fold higher percent of fat mass $(p<0.001)$ than nonobese subjects. Obese patients also had greater lean tissue mass, total bone mineral content $(B M C)$ and total BMD. Daily energy intake of obese children was higher $(p<0.05)$ compared with controls. However, the proportions of protein, fat and carbohydrates in energy intakes of these diets were similar in both studied groups.

$\Rightarrow$ Profile of bone turnover markers between studied groups was different(Table 2). The activity of BALP was higher but the level of OC was lower by about $20 \%(p<0.001)$ in patients compared with controls. CTX-I levels did not differ significantly in both studied groups. Serum leptin levels were elevated $(p<0.001)$ and leptin receptor levels were reduced $(p<0.001)$ in obese children. The ratio of leptin to SOB-R in obese children was about 20 -fold higher than in controls. IGF-1 level was higher by about $10 \%(p<0.05)$, but IGFBP-1 level was above 2 -fold $(p<0.001)$ lower in obese than in controls. Similar mean values of total IGFBP-3 between obese and normal-weight children were obtained, but concentration of functional IGFBP-3 was higher in obese group by about $20 \%(p<0.05)$.

$\Leftrightarrow$ In obese children, significant positive correlations between BALP and leptin, IGF-1, IGFBP-3 and body composition parameters were found (Table 3). Moreover, BALP correlated negatively with leptin receptor and IGFBP-1. By contrast to BALP, OC correlated significantly only with IGFBP-1. No significant correlations between CTX and fat tissue parameters as well as body composition parameters were found.

\section{Conclusions}

We demonstrated that obesity during prepubertal period is associated with increased whole-body bone mass, alterations in leptin/leptin receptor ratio, a growth hormone axis and bone metabolism. Among studied bone markers only BALP may be related to cirulating leptin as well as to factors of IGF system. Further studies concerning lifestyle modification in these children elucidate the influence of weight-loss therapy on bone metabolism.
Table 1.

Anthropometric characteristics and dietary intake of obese and non-obese children

\begin{tabular}{lcc}
\hline & Obese children & Non-obese children \\
\hline Age $(\mathrm{y})$ & $7.9 \pm 1.6$ & $7.7 \pm 1.8$ \\
Gender $(\mathrm{M} / \mathrm{F})$ & $26 / 29$ & $25 / 25$ \\
Height $(\mathrm{cm})$ & $135.3 \pm 11.3^{* *}$ & $127.4 \pm 12.3$ \\
Weight $(\mathrm{kg})$ & $46.7 \pm 11.6^{* * *}$ & $26.6 \pm 6.8$ \\
BMl $\left(\mathrm{kg} / \mathrm{m}^{2}\right)$ & $25.1 \pm 3.23^{* * *}$ & $16.1 \pm 1.9$ \\
BMl z-score & $3.77 \pm 1.42^{* * *}$ & $-0.16 \pm 0.78$ \\
\hline Body composition & & \\
\hline Fat mass $(\%)$ & $42.5 \pm 4.9^{* * *}$ & $21.8 \pm 7.9$ \\
Fat mass $(\mathrm{kg})$ & $19.2 \pm 6.8^{* * *}$ & $5.9 \pm 3.6$ \\
Lean mass $(\mathrm{kg})$ & $25.3 \pm 4.9^{* * *}$ & $19.1 \pm 3.9$ \\
Total BMC $(\mathrm{kg})$ & $1.33 \pm 0.37^{* * *}$ & $0.90 \pm 0.23$ \\
Total BMD $\left(\mathrm{g} / \mathrm{cm}^{2}\right)$ & $0.90 \pm 0.07^{* * *}$ & $0.82 \pm 0.05$ \\
\hline Dietary intake: & & \\
\hline Energy $(\mathrm{kcal} / \mathrm{d})$ & $1750 \pm 480^{*}$ & $1568 \pm 355$ \\
Protein $(\%$ of energy intake) & $13.7 \pm 2.2$ & $13.8 \pm 2.8$ \\
Carbohydrate $(\%$ of energy intake) & $52.2 \pm 6.5$ & $53.0 \pm 6.6$ \\
Fat $(\%$ of energy intake) & $34.1 \pm 6.2$ & $33.2 \pm 5.3$ \\
\hline
\end{tabular}

Data are presented as mean values $\pm S D$;

${ }^{*} p<0.05,{ }^{* *} p<0.01,{ }^{* * *} p<0.001$ obese vs non-obese children

Table 2.

Biochemical measurements in obese and non-obese children

\begin{tabular}{|c|c|c|}
\hline & Obese children & Non-obese children \\
\hline $\operatorname{BALP}(\mathrm{U} / \mathrm{L})^{\mathrm{b}}$ & $136.3 \pm 29.5^{\star \star \star}$ & $112.9 \pm 25.3$ \\
\hline $\mathrm{OC}(\mu \mathrm{g} / \mathrm{L})^{\mathrm{b}}$ & $77.0 \pm 26.1^{* *}$ & $99.1 \pm 28.1$ \\
\hline CTX-I $(\mathrm{ng} / \mathrm{ml})^{\mathrm{b}}$ & $2.01 \pm 0.43$ & $1.92 \pm 0.40$ \\
\hline Leptin $(\mathrm{ng} / \mathrm{ml})^{\mathrm{a}}$ & $32.4(17.9-48.4)^{* * *}$ & $4.50(1.60-6.80)$ \\
\hline 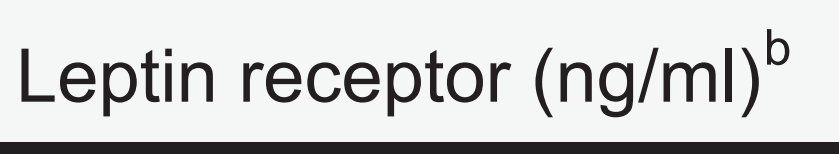 & $24.4 \pm 8.1^{* * *}$ & $41.2 \pm 13.6$ \\
\hline Leptin/Leptin receptor & $1.42(0.74-2.43)^{\star * \star}$ & $0.08 \quad(0.04-0.15)$ \\
\hline IGF-1 $(\mathrm{ng} / \mathrm{ml})^{\mathrm{a}}$ & $147.0(119.7-180.6)^{*}$ & $133.4(109.7-154.4)$ \\
\hline IGFBP-1 $(\mathrm{ng} / \mathrm{ml})^{\mathrm{a}}$ & $6.56(3.20-14.24)^{* * *}$ & $17.34(16.2-22.2)$ \\
\hline IGFBP-3 $(\mu \mathrm{g} / \mathrm{ml})^{\mathrm{b}}$ & $3.27 \pm 0.59$ & $3.20 \pm 0.87$ \\
\hline IGFBP-3f $(\mu \mathrm{g} / \mathrm{ml})^{a}$ & $2.73(2.20-4.00)^{*}$ & $2.32(1.78-3.25)$ \\
\hline
\end{tabular}

aData are presented as median values (25th-75th percentiles)

Data are presented as mean values $\pm S D$

${ }^{*} p<0.05,{ }^{* *} p<0.01,{ }^{* * *} p<0.001$ obese vs non-obese children

Table 3.

Spearman correlation coefficients for serum bone markers, and adipokines, growth factors and body composition parameters in obese children.

\begin{tabular}{l|c|c|c}
\hline & BALP & OC & CTX-I \\
\hline Leptin & $0.400^{* *}$ & 0.091 & -0.093 \\
\hline Leptin receptor & $-0.305^{*}$ & -0.190 & -0.056 \\
\hline IGF-1 & $0.380^{* *}$ & 0.172 & 0.058 \\
\hline IGFBP-1 & $-0.337^{*}$ & $-0.421^{* *}$ & -0.272 \\
\hline IGFBP-3 & $0.298^{*}$ & 0.056 & 0.131 \\
\hline IGFBP-3f & $0.329^{*}$ & -0.153 & 0.150 \\
\hline BMI & $0.361^{* *}$ & 0.130 & -0.060 \\
\hline$\%$ Fat mass & $0.492^{* * *}$ & 0.121 & -0.103 \\
\hline Total BMC & $0.551^{* * *}$ & 0.097 & 0.017 \\
\hline
\end{tabular}

Statistically significant correlations coefficients: ${ }^{*} p<0.05, \quad{ }^{* *} p<0.01,{ }^{* * *} p<0.001$. 